\title{
The Effect of Meloxicam NSAID Therapy on the Change in Vigor, Suckling Reflex, Blood Gas Measures, Milk Intake and Other Variables in Newborn Dairy Calves
}

\author{
Murray $\mathrm{CF}^{*}$, Duffield $\mathrm{TF}^{1}$, Haley $\mathrm{DB}^{1}$, Pearl $\mathrm{DL}^{1}$, Veira $\mathrm{DM}^{2}$, Deelen $\mathrm{SM}^{1}$ and Leslie $\mathrm{KE}^{1}$ \\ ${ }^{1}$ Department of Population Medicine, University of Guelph, Ontario, Canada \\ ${ }^{2}$ Pacific Agri-Food Research Centre, Agriculture and Agri-Food Canada, British Columbia, Canada
}

${ }^{*}$ Corresponding author: Murray CF, Department of Population Medicine, University of Guelph, 50 Stone Road East, Guelph, Ontario, Canada, N1G 2W1, E-mail: christine.murray@trouwnutrition.com

Citation: Murray CF, Duffield TF, Haley DB, Pearl DL, Veira DM, et al. (2016) The Effect of Meloxicam NSAID Therapy on the Change in Vigor, Suckling Reflex, Blood Gas Measures, Milk Intake and Other Variables in Newborn Dairy Calves. J Vet Sci Anim Husb 4(1): 103. doi: 10.15744/2348-9790.4.103

Received Date: September 13, 2015 Accepted Date: January 15, 2016 Published Date: January 18, 2016

\begin{abstract}
The objective of this research was to determine the effect of the administration of meloxicam to newborn dairy calves on physiological and behavioral measures of calf vigor, as well as future health, milk intake and growth. A total of 284 Holstein heifer and bull calves were enrolled at birth from two dairy farms to participate in this randomized double-blind clinical field trial. At enrollment, calves were assessed for vigor using the VIGOR score sheet and subsequently administered either a $1.0 \mathrm{~mL}$ subcutaneous injection of meloxicam $(20 \mathrm{mg} / \mathrm{mL})$ or $1.0 \mathrm{~mL}$ of placebo solution. Calves were grouped into 3 categories based on the timing of birth relative to the next study technician visit to the farm: $<2 \mathrm{~h}, 2-6 \mathrm{~h}$ or $1-4 \mathrm{~d}$ of age. Based on the category, specific measures were collected including heart and respiration rate, temperature, suckling reflex and blood gas concentrations. Subsequently, each calf was measured for growth and assessed for health at 1,2,3 and 8 weeks of age. Calves born from a hard pull had reduced vigor as compared to calves born unassisted $(P<0.001)$. Calves with poor vigor had lower blood $\mathrm{pH}$ as $\mathrm{pCO}_{2}$ increased, compared to calves with excellent vigor $(P=0.001)$. Calves that received meloxicam following birth had a significantly greater improvement in vigor $(P=0.02)$ and suckling reflex $(P=$ $0.01)$ following treatment than calves that received the placebo solution. Significantly greater milk intake was seen in calves that were treated with meloxicam following birth $(P=0.04)$, and in calves with better health throughout the 8 week follow-up period $(P=0.002)$. Meloxicam therapy shows considerable promise for improving short-term challenges with newborn calf vigor, and may be beneficial for growth, health and long-term productivity resulting from improved pre-weaning milk intakes.
\end{abstract}

Keywords: Dystocia; Calf; Vigor; Pain; Therapy

\section{Introduction}

The transition from fetal to neonatal life can be both traumatic and stressful for a newborn calf [1]. The degree of stress and trauma may be highly variable, and is dependent on calf size, calf presentation, pelvic dimensions of the dam, strength of contractions, insufficient dilation of the cervix and uterine torsion [2]. Any one of these factors alone, or combined, may result in a difficult parturition, termed dystocia. Dystocia may be defined as a difficult or abnormal calving due to prolonged parturition, or due to a prolonged or difficult assisted calf removal [3]. Stress in calves resulting from dystocia greatly increases the risks of both early morbidity and mortality, and can pose substantial costs to the dairy industry [4,5]. Reduced newborn calf vigor may be responsible for a proportion of the losses that are associated with dystocia. Vigor, interchangeably used with the word vitality, can be defined as having the capacity to live and grow with physical and mental energy and strength [6]. Reduced newborn calf vigor from dystocia can result from injury, inflammation, inability to maintain homeostasis, as well as from hypoxia and acidosis [1,7-9]. These physiological effects can have behavioral repercussions, such as having reduced motivation to perform natural behaviors for survival, including standing up and suckling colostrum after birth [10].

Attempts have been made to assess the vigor of newborns through scoring systems. One scoring system for humans that has had widespread implementation is the Apgar score created by Virginia Apgar in the 1950's [11]. Since then, it has become a standard procedure to test the vital signs of human babies within minutes of birth. Variations of this scoring system have been studied in other species, such as the newborn pig [12], horse [13], dog [14], and calf [15]. Parameters that were included in these scoring systems were easily evaluated without complex tools or invasive measures. Parameters such as heart and respiratory rate, reflexes, mobility and mucous membrane colour were included. These scores generally give a good indication of the state of newborn vigor, and whether the animal needs further intervention for welfare, health and survival. Recently, the usefulness of a novel calf VIGOR assessment tool to measure birth trauma and associations with future health and growth was evaluated [16]. In this study, the VIGOR score evaluated the Visual Appearance, Initiation of movement, General responsiveness, Oxygenation, and heart and respiratory Rates of the newborn calf. Overall, the calf VIGOR score was found to be a good indicator of trauma at calving. 
Traditional methods that have been suggested to improve the viability of newborn calves include artificial respiration, respiratory stimulants, supplemental oxygen, buffer therapy for acidosis, thermal support and manual colostrum feeding [3,17]. A more novel strategy to improve calf vigor and survival is the administration of non-steroidal anti-inflammatory drugs (NSAIDs) for the alleviation of pain and inflammation following dystocia [18]. Meloxicam is an NSAID that preferentially inhibits cyclo-oxygenase 2 (COX-2) enzymes to reduce prostaglandin synthesis and inflammation. Meloxicam also has anti-endotoxic and anti-pyretic effects in cattle $[18,19]$. However, there is virtually no research investigating the benefits of NSAID use in calves following dystocia. It is hypothesized that calves suffering from inflammation and pain from a difficult birth may benefit from the administration of NSAIDs, particularly meloxicam, following calving. Furthermore, it is hypothesized that meloxicam will be positively associated with newborn calf vigor, health and subsequent performance. The objective of this research was to determine the effect of the administration of meloxicam to newborn dairy calves on physiological and behavioral measures of calf vigor, as well as future health, milk intake and growth.

\section{Materials and Methods}

\section{Calf Enrollment and Study Farms}

Before the study commenced, the experiment was approved by the University of Guelph Animal Care Committee (\#10R084, Guelph, ON, Canada), and all work with animals was done according to the guidelines set by the Canadian Council on Animal Care [20].

Male and female Holstein calves born on two dairy farms were enrolled on this trial from January to June, 2011. Farm 1 was located in southern Ontario, whereas Farm 2 was located in the Fraser Valley of British Columbia. These two farms were selected based on proximity to research technicians and willingness to participate in the study. Sample size was calculated using the 'sampsi' command in Stata-IC 10.1 (StataCorp, College Station, Texas), using data from a previous study investigating the health and growth of meloxicam-treated calves [16]. Sample size was estimated by comparison of means with a power of $80 \%$ and confidence level of $95 \%$. It was determined that there was a requirement of approximately 100 calves per experimental treatment group.

\section{Vigor Assessment}

At the time of discovery of a newborn calf, prior to colostrum feeding, the producer, farm worker or research technician completed a VIGOR score sheet (Table 1). VIGOR, as used in this paper, is an acronym for the assessment of Visual appearance, Initiation of movement, General responsiveness, Oxygenation, as well as heart and respiration Rates. This was a novel scoring system developed by the authors for the purposes of assessing newborn calf vigor in a previous investigation [16] and in the current study.

Scores for each of these criteria were added together to get a composite VIGOR score. The higher the score, the less vigorous the calf was deemed to be. The latency from birth to when the calf was assessed with the VIGOR score sheet was also recorded. This latency from birth variable was later categorized into 0-30 min, $30 \mathrm{~min}-1.5 \mathrm{~h}, 1.5-3 \mathrm{~h}$ and $>3 \mathrm{~h}$ to avoid violating the linearity assumption in subsequent regression analyses.

\section{Treatments, Randomization, and Blinding}

Immediately following VIGOR assessment, calves were randomly assigned to receive a subcutaneous injection from a numbered individual treatment vial containing one of two treatments: $1.0 \mathrm{~mL}$ of either meloxicam (Metacam ${ }^{\oplus}$, Boehringer Ingelheim, Burlington, ON), with a target dosage of $0.5 \mathrm{mg} / \mathrm{kg}$, or a placebo solution. Each $\mathrm{ml}$ of Metacam ${ }^{\circledast}$ for injection contained $20.0 \mathrm{mg}$ meloxicam and $150 \mathrm{mg}$ ethanol (as preservative). The placebo used in this study was a visually identical product to Metacam ${ }^{\otimes}$, and had an identical base formulation of the product without the active ingredient, meloxicam.

This study was conducted as a randomized double-blinded clinical trial. Treatment allocation was randomized using a random number generator. Treatments were randomized so that every 10 vials included 5 meloxicam and 5 placebo treatments. The experimental treatment vials were distributed to farms in multiples of 10 to ensure that close to an equal number of treated and control calves were enrolled on each farm.

Following treatment administration to a newborn calf, the producer or farm worker filled out a birth record documenting information about the birth event, including: date, time, calving assistance, quantity and source of colostrum fed to each calf, and the randomized experimental treatment vial number administered to the calf. Birth time was recorded by producers as a time interval rather than an exact time. Season of birth was determined by calving date and categorized into winter (December $21^{\text {st }}$ to March $20^{\text {th }}$ ) or spring (March $21^{\text {st }}$ to June $19^{\text {th }}$ ).

\section{Farm Visits and Calf Sampling}

Trained research technicians visited the farm three times per week to assess newly enrolled animals, and to collect measurements and samples from previously enrolled animals. Newly enrolled calves were grouped into age categories, dependent upon the timing of technician visit: less than $2 \mathrm{~h}$, between 2 to $6 \mathrm{~h}$ and between 1 to $4 \mathrm{~d}$ of age. Calves that were between 7 and $24 \mathrm{~h}$ of age upon technician visit were left until the subsequent visit to be sampled ( 1 to 4 days of age), as it was deemed to be too late after birth to measure blood-gas parameters and too early for serum total protein (STP) determinations. Calves that were enrolled at either less than $2 \mathrm{~h}$ or between 2 and $6 \mathrm{~h}$ of age were assessed again on the next visit to the farm when they were 1 to $4 \mathrm{~d}$ old. Particular parameters were measured at each age category as seen in Table 2. 


\begin{tabular}{|c|c|c|c|c|}
\hline \multicolumn{5}{|c|}{ Visual Appearance } \\
\hline Score & $\mathbf{0}$ & 1 & 2 & 3 \\
\hline 1. Meconium Staining & $\begin{array}{l}\text { Normal: no } \\
\text { staining }\end{array}$ & $\begin{array}{l}\text { Slight: around } \\
\text { anal/tail head area }\end{array}$ & $\begin{array}{l}\text { Moderate: } \\
\text { extending over } \\
\text { body }\end{array}$ & $\begin{array}{l}\text { Severe: } \\
\text { completely } \\
\text { covered }\end{array}$ \\
\hline 2. Tongue/Head & $\begin{array}{l}\text { Normal (no } \\
\text { swelling, tongue } \\
\text { not protruding) }\end{array}$ & $\begin{array}{l}\text { Tongue protruding } \\
\text { but not swollen }\end{array}$ & $\begin{array}{l}\text { Tongue protruding } \\
\text { and swollen }\end{array}$ & $\begin{array}{l}\text { Head and tongue } \\
\text { swollen, tongue } \\
\text { protruding }\end{array}$ \\
\hline \multicolumn{5}{|c|}{ Initiation of Movement } \\
\hline 3. Calf Movement & Standing/walking & Attempts to stand & Sternal & On side, no efforts to rise \\
\hline Taken within & $0-30 \mathrm{~min}$ & $30 \mathrm{~min}-1.5 \mathrm{~h}$ & $1.5 \mathrm{~h}-3 \mathrm{~h}$ & $>3 \mathrm{~h}$ \\
\hline \multicolumn{5}{|c|}{ General Responsiveness } \\
\hline $\begin{array}{l}\text { 4. Head shake in response to } \\
\text { straw in nasal } \\
\text { cavity }\end{array}$ & $\begin{array}{l}\text { Shakes head } \\
\text { vigorously }\end{array}$ & Moves head away & Twitches or flinches & Does not respond \\
\hline 5. Tongue Pinch & $\begin{array}{c}\text { Actively withdraws } \\
\text { tongue }\end{array}$ & $\begin{array}{l}\text { Attempts to } \\
\text { withdraw }\end{array}$ & Twitches tongue & Does not respond \\
\hline $\begin{array}{c}\text { 6. Eye Reflex (in response to } \\
\text { Touching eyeball) }\end{array}$ & $\begin{array}{l}\text { Actively blinks and closes } \\
\text { eye }\end{array}$ & Slow to blink & Does not respond & - \\
\hline \multicolumn{5}{|c|}{ Oxygenation } \\
\hline $\begin{array}{l}\text { 7. Mucous Membrane } \\
\text { Colour }\end{array}$ & Bright Pink & Light Pink & Brick Red & White/blue \\
\hline 8. Length of Tongue* & $<50 \mathrm{~mm}$ & $50-61 \mathrm{~mm}$ & $>62 \mathrm{~mm}$ & - \\
\hline \multicolumn{5}{|c|}{ Rates } \\
\hline 9. Heart Rate & $80-100$ bpm & $>100 \mathrm{bpm}$ & $<80 \mathrm{bpm}$ & - \\
\hline 10. Respiration Rate R $^{* * *}$ & $\sim 24-36 \mathrm{bpm}$ & $\sim 24 \mathrm{bpm}$ & $\sim>36 \mathrm{bpm}$ & - \\
\hline
\end{tabular}

${ }^{*}$ Measure from lips. Record this measurement only if within 5 minutes of calving

${ }^{* *}$ Place hand on the calf's chest. Take pulse for 15 seconds then multiply by 4 to get beats per minute (bpm)

${ }^{* *}$ View and/or place hand on the calf's abdomen to count the approximate number of breaths for 15 seconds and multiply by 4 to get breaths per minute (bpm)

Table 1: VIGOR score sheet

\begin{tabular}{|c|c|}
\hline Time after birth & Parameters measured \\
\hline$<2$ hours of age & $\begin{array}{l}\text { Pre-treatment: } \\
\text { - } \\
\text { - } \text { Rlood gases }^{\mathrm{a}} \\
\text {-Respiration } \& \text { heart rate }{ }^{\mathrm{b}} \\
\text { - } \text {-Suckling reflex }{ }^{\mathrm{c}} \\
\text {-Oxygen saturation }{ }^{\mathrm{d}} \\
\text { Post-treatment (1-2 h post treatment): } \\
\text {-VIGOR assessment } \\
\text {-Suckling reflex }\end{array}$ \\
\hline Between 2 and 6 hours of age & $\begin{array}{l}\text { Post-treatment (1-6 h post treatment): } \\
\text {-VIGOR assessment } \\
\text {-Rectal temperature } \\
\text {-Respiration \& heart rate } \\
\text {-Suckling reflex } \\
\text {-Oxygen saturation }{ }^{\mathrm{d}}\end{array}$ \\
\hline 1 to 4 days of age & $\begin{array}{l}\text {-Blood for STP analysis } \\
\text {-Rectal temperature } \\
\text {-Respiration \& heart rate } \\
\text {-Suckling reflex } \\
\text {-Oxygen saturation } \\
\text { - }{ }^{\mathrm{d}} \\
\text {-Weight }^{\mathrm{f}} \\
\text {-Height }^{\mathrm{g}} \\
\text {-Health scores }^{\mathrm{h}}\end{array}$ \\
\hline 8 week follow-up period & $\begin{array}{l}\text { At 2, } 3 \text { and } 8 \text { weeks of age: }^{\mathrm{f}} \\
\text { - Weight } \\
\text { - }{ }^{\mathrm{f}} \\
\text { - Height }{ }^{\mathrm{g}} \\
\text { - Health scores } \\
\text { - Fecal samples (2 \& } 3 \text { weeks) }\end{array}$ \\
\hline
\end{tabular}


${ }^{a}$ Collected from the jugular vein into a heparinized syringe (GasLyte arterial blood sampler - Vital Signs, CO). Within five minutes of collection, blood gas and electrolyte analysis was performed using IRMA TRUpoint ${ }^{\circledR}$ Blood Analysis System (ITC, Edison, New Jersey, USA)

bPlaced a hand over the calf's diaphragm or heart. Counted respiratory movements or heart beats for 15 sec and multiplied by 4

${ }^{c}$ Finger test on a 3 point scale; 1: weak or no suckling, 2: moderate suckling reflex, 3: strong suckling reflex. A second measure of suckling reflex was recorded using a VWR Traceable ${ }^{\varpi}$ Printing Manometer (VWR 89094-728; Mississauga, ON) outfitted with a peach teat (Christchurch, NZ). Values in pounds per square inch, representing suckling strength/vacuum and pressure exerted on the teat

dNonin Hand-Held Veterinary Pulse Oximeter (Model 8500AV) with a rectal probe

${ }^{\mathrm{e}}$ Transported on ice to the laboratory. Centrifuged at $2500 \mathrm{rpm}$ for 12 minutes at $\sim 20^{\circ} \mathrm{C}$. Serum was analyzed for serum total protein (STP) using a digital refractometer (KS - 0050, Kernco Instruments)

fHeart girth weight tape for Holstein calves (Nasco, Modesto CA, USA)

Livestock height measuring tape (Ketchum Manufacturing Inc. KF-1037-065)

${ }^{\mathrm{h}}$ Graded scoring system with scores ranging from 0 to 4 for attitude, eye discharge, ear droop, nasal discharge and fecal consistency [21]. A higher health score was indicative of a less healthy calf [21]

Table 2: Calf sampling schedule: parameters measured on calves in each age category, dependent upon technician visit

8 Week Follow-up Period: All calves enrolled on the trial were reassessed at 2, 3 and 8 weeks of age (Table 2). On Farm 2, bull calves were sold following the assessment at week 3 and were therefore unavailable for follow-up assessment at week 8 . The four health scores given to each calf were added together to create a cumulative total pre-weaning health score. At 2 and 3 weeks of age only, fecal samples were collected from the first 87 calves enrolled on the study and analyzed using BIO K 248 Duo RotaCryptosporidium Strips (Bio-X Diagnostics SPRL, Jemelle, Belgium) for shedding of rotavirus and Cryptosporidium parvum fecal pathogens.

During the course of study, all illness and treatment events were recorded by the producer. Treatment was defined as the administration of a product to an animal in response to an illness event during the study period. For the purpose of this study, only antibiotics used to treat either diarrhea or respiratory disease were considered. Treatment for diarrhea and respiratory disease were used as separate variables, and also compiled into one continuous variable as the number of courses of antibiotic treatments for each calf throughout their 8 week duration on the study.

Oxygen saturation values measured with the pulse oximeter were not found to be correlated with the actual values from bloodgas analysis. Thus, the use of the pulse oximeter in this study was discontinued three quarters of the way through the trial's completion. Values obtained from the pulse oximeter were not used in statistical analyses.

\section{Calf Housing and Management}

On Farm 1, newborn calves were left with their dam in the maternity pen bedded with a mixture of straw and sawdust until they were cleaned of amniotic fluid and until a member of the farm staff was able to move them. Prior to movement to a neonatal calf area directly across from the maternity pens, calves were assessed using the VIGOR score and injected with experimental treatment (meloxicam or placebo). The neonatal calf area was also bedded with straw and sawdust. Calves were kept in this area until they could be transported to a separate calf barn, which was within 2 days of birth. On Farm 2, calves stayed in the maternity pen with the dam (deep bedded straw over sand) until after they were assessed using the VIGOR score and injected with the experimental treatment. Following treatment administration, calves were moved to a separate calf housing facility.

Farms 1 and 2 both had separate calf housing facilities away from the main barn, which contained individual calf stalls, as well as a set of group pens with $\mathrm{DeLaval}^{\oplus}$ automatic milk feeders. Once transported to the separate calf facility, calves were placed into individual stalls.

While in the individual stalls, calves on Farm 1 were offered $3 \mathrm{~L}$ of whole milk twice per day by bottle and had free access to starter. Between 2 and 4 weeks of age, calves were moved from the individual stall to a group pen, where they were grouped by age. Group pens contained 20 calves per pen, and were bedded with a base of sawdust with straw on top. Calves received a maximum of $8 \mathrm{~L}$ of whole milk per day from an automatic milk feeder (CF 1000 CS Combi, DeLaval Inc., Tumba, Sweden), and had free access to calf starter and water.

On Farm 2, calves were fed $4 \mathrm{~L}$ of whole milk twice per day by bottle, and had access to water when in the individual stalls. Calves were kept in the stalls for 5-10 days on average, and then moved to a group pen. Group pens on Farm 2 were bedded with shavings and contained up to 10 calves per pen. These calves were offered up to $12 \mathrm{~L}$ of whole milk per day from an automated milk feeder (CF 1000 CS Combi, DeLaval Inc., Tumba, Sweden). Calf starter, hay and water were also provided.

Milk intakes, drinking speed and the number of unrewarded visits (without milk) and rewarded visits (with milk) to the feeder were monitored and recorded for each calf's first 30 days in the group pen, using the KalbManagerWIN computer program by Forster Technik ${ }^{\oplus}$. On Farm 1, milk intake and feeding behavior data were collected on both heifer and bull calves that were enrolled in the study. On Farm 2, complete feeding data could not be collected on bull calves as they were sold prior to study completion.

\section{Statistical Analysis}

Data were entered in Microsoft Excel (Microsoft, USA) and exported into Stata-IC 10.1 (StataCorp, College Station, Texas) for variable screening and statistical modeling. A causal diagram was built to examine the possible relationships that should be tested by the model. All variables were examined with descriptive statistics to determine their distributions and to look for missing values. If abnormal values were detected, data were checked against the original hard copy of data. 
Univariable regression analyses: Individual linear relationships were assessed using the 'reg' command in Stata to determine the significance of associations of interest between a series of dependent variables and individual independent variables of interest, while controlling for farm as a fixed effect. Independent variables included in these models included calving assistance, bloodgas variables, experimental treatment, total VIGOR score, milk intake, number of antibiotic treatments and fecal test results. Dependent variables were as follows: pre experimental treatment VIGOR score, pre to post experimental treatment change in VIGOR score, pre to post experimental treatment change in suckling reflex using the finger and manometer test, STP, ADG and health scores.

The significance of individual logistic relationships were investigated using the 'logit' command in Stata to determine if meloxicam treatment or health scores (independent variables) were associated with testing positive for fecal pathogens (dependent variable), while controlling for farm as a fixed effect. In all analyses, tongue length was excluded from the total VIGOR score tabulation, as there were limited observations in which this variable could be recorded.

Multivariable regression models: Four separate multivariable linear regression models were constructed to determine factors associated with the following dependent variables: $\mathrm{pH}$ at $<2 \mathrm{~h}$ after birth, 8 week ADG, milk intake and total 8 week health score. In addition, a Poisson regression model was built using the number of antibiotic treatment events as the outcome. The exposure for this model was days at risk for antibiotic treatment.

All variables hypothesized to be related to the outcome of interest were screened for unconditional associations with the outcome variable in univariable regression analyses, while controlling for farm as a fixed effect. Any predictor variables that were associated with the outcome using a liberal significance level $(\alpha=0.2)$ were considered for inclusion in the final model.

Spearman correlation coefficients were calculated for all main effects variables that were considered for inclusion in the final model to avoid issues associated with collinearity. Consequently, if the correlation coefficient between two variables had an absolute value greater than 0.8 , the variable that made the most biological sense, or had the fewest missing observations, was included in the multivariable model building process.

Linearity between continuous independent variables and the outcome were assessed graphically using locally weighted regression (lowess curves). For the Poisson model, the lowess curves were built using the continuous independent variable and the log of the antibiotic treatment rate. If a variable was non-linear, a quadratic term was constructed and tested in the model. If the quadratic term was significant $(P \leq 0.05)$ in the model and the relationship was adequately modeled using a curve, the quadratic term was retained in the model. If not, the quadratic term was removed and log and square root transformations were assessed for linearity and significance. If none of the presented transformations appeared to improve linearity, the variable was categorized.

All potential confounding variables with the outcome were included in the model building process. For all models, farm was considered a potential confounding variable and was included as a fixed effect. A confounder was defined as a non-intervening variable whose removal resulted in a $>25 \%$ change in the coefficient of a significant variable. Regardless of the $P$-value, a confounding variable was retained in the model.

Interaction terms between experimental treatment and main effects variables were tested in each multivariable model. In addition, interaction terms between VIGOR score and main effects were investigated. Statistically significant interaction terms $(P \leq 0.05)$ were considered to be evidence of interaction, and were retained in the final model. Interaction effects were assessed graphically and through contrast statements. Main effects variables were included in the final model if $P \leq 0.05$, if they were a confounding variable or part of a significant interaction term.

To satisfy the assumption of homoscedasticity and normality for linear models, the following tests were performed. A CookWeisberg test was performed, using a non-significant test $(P>0.05)$ as evidence for homoscedasticity. Homoscedasticity was also examined graphically by plotting the standardized residuals against the predicted values. A Shapiro-Wilk's test was performed on the standardized residuals, with a non-significant test $(P>0.05)$ suggesting normality. Standardized residuals, as well as Anscombe residuals for Poisson regression, were examined graphically to look for outliers and observations with high leverage. Influential observations were identified by examining Cook's distance, DFITS and/or DFBETA graphically, depending on the model type. Outliers and influential observations were examined for recording errors and to see if their removal resulted in a change in interpretation of the model(s).

\section{Results}

\section{Animal Enrollment}

A total of 284 Holstein heifer and bull calves were enrolled in this study from 2 farms. Farm 1 enrolled 259 calves and Farm 2 enrolled 25 calves into the study.

Although treatment assignment was not stratified by calving assistance, it is noteworthy that the experimental treatments were relatively evenly distributed amongst categories of calving assistance. In the meloxicam group, 64\% of calves were born from an easy pull, $20 \%$ were born unobserved, $11 \%$ from a hard pull and $6 \%$ were observed but unassisted. In the placebo group, $55 \%$ of calves were born from an easy pull, 33\% from an unobserved calving, $6 \%$ from a hard pull and 6\% from an observed but unassisted calving.

\section{Calf Vigor}

Calf VIGOR score differed by farm. Calves on Farm 2 had significantly higher VIGOR scores (worse vigor) than calves on Far- 
m $1(\beta=3.89 ; 95 \% \mathrm{CI}=2.84$ to $4.95 ; P<0.001)$. The mean $( \pm$ standard deviation $[\mathrm{SD}])$ VIGOR score for calves on Farm 1 was 3.7 \pm 2.60 , while on Farm 2, the mean VIGOR score was 7.6 \pm 2.04 . Mean VIGOR score by sex and calving assistance can be seen in Table 3. Controlling for farm as a fixed effect, there was a significant association between VIGOR score and calving assistance. Calves born from an easy or hard pull had significantly higher scores (worse vigor) than calves born from an unobserved calving (Table 4). Blood $\mathrm{pH}$ and $\mathrm{pCO}_{2}<2 \mathrm{~h}$ after birth were not significantly associated with VIGOR score (Table 4).

In a subset of the study population, 61 calves were assessed with a second VIGOR score 1-6 h post treatment with meloxicam or placebo. The average $( \pm S D)$ time to the second VIGOR assessment was $2.4 \pm 1.1 \mathrm{~h}$ after birth. It was found that calves who received meloxicam following birth had a significantly greater improvement in vigor (lower score) from the first to the second VIGOR score assessment than placebo treated calves (Table 5).

\begin{tabular}{|c|c|c|c|c|}
\hline & Unobserved & Observed but Unassisted & Easy Pull & Hard Pull \\
\hline $\mathbf{n}$ & $\mathbf{7 1}$ & $\mathbf{1 6}$ & $\mathbf{1 6 2}$ & $\mathbf{2 3}$ \\
\hline VIGOR score & & & & \\
\hline Heifer & $2.4 \pm 1.91$ & $4.5 \pm 2.60$ & $3.8 \pm 2.43$ & $6.3 \pm 4.57$ \\
\hline Bull & $3.1 \pm 1.90$ & $6.6 \pm 1.99$ & $4.5 \pm 2.60$ & $7.8 \pm 3.58$ \\
\hline Heifer \& bull & $2.8 \pm 1.92$ & $5.4 \pm 2.50$ & $4.2 \pm 2.54$ & $7.5 \pm 3.70$ \\
\hline & & & & \\
\hline STP & & & & $6.0 \pm 0.81$ \\
\hline Heifer & $6.2 \pm 0.73$ & $5.8 \pm 0.83$ & $5.8 \pm 0.81$ & $5.3 \pm 1.00$ \\
\hline Bull & $6.1 \pm 0.62$ & $5.8 \pm 0.74$ & $5.9 \pm 0.81$ & $5.9 \pm 0.84$ \\
\hline Heifer \& bull & $6.1 \pm 0.76$ & $5.8 \pm 0.77$ & 143 & 20 \\
\hline $\mathbf{n}$ & 61 & 10 & & \\
\hline ADG (kg) & & & $0.59 \pm 0.18$ & $0.64 \pm 0.18$ \\
\hline Heifer & $0.64 \pm 0.15$ & $0.77 \pm 0.19$ & $0.64 \pm 0.14$ & $0.64 \pm 0.14$ \\
\hline Bull & $0.68 \pm 0.14$ & & $0.64 \pm 0.18$ & $0.64 \pm 0.14$ \\
\hline Heifer \& bull & $0.68 \pm 0.14$ & $0.73 \pm 0.20$ & & \\
\hline
\end{tabular}

Table 3: VIGOR score, STP, ADG and 8 week weight gain by level of calving assistance (mean \pm standard deviation)

\begin{tabular}{|c|c|c|c|c|}
\hline \multirow{2}{*}{ VIGOR Score } & \multirow{2}{*}{ Coefficient } & \multicolumn{2}{|c|}{ 95\% CI } & \multirow{2}{*}{$P$-value } \\
\hline & & lower limit & upper limit & \\
\hline \multicolumn{5}{|l|}{ Calving assistance } \\
\hline Unobserved & Ref & - & - & - \\
\hline Observed but unassisted & 0.57 & -0.83 & 1.97 & 0.42 \\
\hline Easy pull & 1.06 & 0.41 & 1.72 & 0.002 \\
\hline Hard pull & 4.46 & 3.36 & 5.55 & $<0.001$ \\
\hline \multicolumn{5}{|l|}{ Farm } \\
\hline 1 & Ref & - & - & - \\
\hline 2 & 3.69 & 2.63 & 4.75 & $<0.001$ \\
\hline $\mathrm{pH}<2 \mathrm{~h}$ from birth & -1.05 & -11.08 & 8.98 & 0.83 \\
\hline \multicolumn{5}{|l|}{ Farm } \\
\hline 1 & Ref & - & - & - \\
\hline 2 & 3.17 & 1.51 & 4.83 & $<0.001$ \\
\hline $\mathrm{pCO}_{2}<2 \mathrm{~h}$ from birth & -0.026 & -0.10 & 0.052 & 0.50 \\
\hline \multicolumn{5}{|l|}{ Farm } \\
\hline 1 & Ref & - & - & - \\
\hline 2 & 3.46 & 1.82 & 0.052 & $<0.001$ \\
\hline
\end{tabular}

Ref - Referent category

Table 4: Linear regression models showing the effect of calving assistance, blood $\mathrm{pH}$ and partial pressure of carbon dioxide $\left(\mathrm{pCO}_{2}\right) 2 \mathrm{~h}$ after birth on VIGOR score, including farm as a fixed effect 
Total VIGOR score was not significantly associated with STP, after controlling for farm and age at blood sampling for STP as fixed effects $(\beta=-0.15 ; 95 \% \mathrm{CI}=-0.55$ to $0.25 ; P=0.46)$. In addition, total VIGOR score was not significantly associated with suckling reflex using either the finger test $(\beta=-0.23 ; 95 \% \mathrm{CI}=-0.65$ to $0.18 ; P=0.27)$ or manometer $\operatorname{method}(\beta=-0.28 ; 95 \% \mathrm{CI}=-1.74$ to $1.18 ; P=0.70)$. However, it was found that calves that were treated with meloxicam had a significantly improved suckling reflex based on the finger test following treatment (Table 5). Readings from the manometer showed that the pressure exerted on the peach teat was not significantly greater following treatment with meloxicam than in placebo-treated calves (Table 5).

\begin{tabular}{|c|c|c|c|c|c|c|}
\hline \multirow{2}{*}{$\begin{array}{c}\text { Difference in VIGORScore pre to post } \\
\text { treatment }\end{array}$} & \multirow{2}{*}{$\mathbf{n}$} & \multirow{2}{*}{ Mean \pm SD } & \multirow{2}{*}{ Coefficient } & \multicolumn{2}{|c|}{$95 \% \mathrm{CI}$} & \multirow{2}{*}{$P$-value } \\
\hline & & & & lower limit & upper limit & \\
\hline \multicolumn{7}{|l|}{ Treatment } \\
\hline Meloxicam & 28 & $-1.75 \pm 1.99$ & -1.48 & -2.74 & -0.21 & 0.023 \\
\hline Placebo & 33 & $0.00 \pm 2.66$ & Ref & - & - & - \\
\hline \multicolumn{7}{|l|}{ Farm } \\
\hline 1 & & & Ref & - & - & - \\
\hline 2 & & & -1.06 & -2.33 & 0.22 & 0.10 \\
\hline Time of $2^{\text {nd }}$ VIGOR assessment & & & 0.0012 & -0.0087 & 0.011 & 0.81 \\
\hline \multicolumn{7}{|l|}{$\begin{array}{l}\text { Finger Test: Difference in suckling } \\
\text { reflex pre to post treatment (1-3) }\end{array}$} \\
\hline \multicolumn{7}{|l|}{ Treatment } \\
\hline Meloxicam & 19 & $0.75 \pm 0.79$ & 0.65 & 0.14 & 1.16 & 0.014 \\
\hline Placebo & 15 & $0.067 \pm 0.59$ & Ref & - & - & - \\
\hline \multicolumn{7}{|l|}{ Farm } \\
\hline 1 & & & Ref & - & - & - \\
\hline 2 & & & 0.18 & -0.39 & 0.75 & 0.53 \\
\hline Time of post suckling assessment & & & -0.0026 & -0.0083 & 0.0031 & 0.35 \\
\hline \multicolumn{7}{|l|}{$\begin{array}{l}\text { Manometer: Difference in suckling } \\
\text { pressure pre to post treatment (psi) }\end{array}$} \\
\hline \multicolumn{7}{|l|}{ Treatment } \\
\hline Meloxicam & 19 & $0.41 \pm 0.77$ & 0.43 & -0.04 & 0.90 & 0.072 \\
\hline Placebo & 15 & $-0.0013 \pm 0.46$ & Ref & - & - & - \\
\hline \multicolumn{7}{|l|}{ Farm } \\
\hline 1 & & & Ref & - & - & - \\
\hline 2 & & & -0.32 & -0.85 & 0.22 & 0.24 \\
\hline Time of post sucking assessment & & & 0.001 & -0.0042 & 0.0062 & 0.69 \\
\hline
\end{tabular}

Table 5: Linear regression models showing the effect of experimental treatment on the change in VIGOR score and suckling reflex using the finger test (1 to 3; weak to strong suckling reflex) and the manometer test (pounds per square inch [psi]), accounting for farm and time of VIGOR and suckling assessment after birth as fixed effects. Mean \pm standard deviation (SD) of the change in VIGOR score, suckling reflex and suckling pressure pre to post treatment with meloxicam and placebo. (Ref- Referent category)

\section{Acidosis}

Data from 34 calves were used to model the association of various factors with low blood $\mathrm{pH}$ in calves $<2 \mathrm{~h}$ of age (Table 6 ). Calves with higher blood bicarbonate concentration at $<2 \mathrm{~h}$ of age had higher $\mathrm{pH}$. A significant interaction was found between $\mathrm{pCO}_{2}$ and total VIGOR score. Calves with poor VIGOR scores had lower blood $\mathrm{pH}$ as levels of $\mathrm{pCO}_{2}$ increased, compared to calves with excellent VIGOR scores (Figure 1).

\begin{tabular}{|c|c|c|c|c|}
\hline $\mathbf{p H}$ at $<\mathbf{2} \mathbf{~ h}$ & Coefficient & \multicolumn{2}{|c|}{$\mathbf{9 5 \%}$ Confidence Interval } & P-value \\
\hline & & lower limit & upper limit & \\
\hline $\mathrm{HCO}_{\mathbf{3}}$ at $\mathbf{2} \mathbf{~}$ & 0.014 & 0.014 & 0.015 & $<0.001$ \\
\hline $\mathbf{p C O}_{2}$ at 2 h & -0.0081 & -0.0091 & -0.0070 & $<0.001$ \\
\hline Total VIGOR score & -0.021 & -0.030 & -0.011 & $<0.001$ \\
\hline $\begin{array}{c}\text { Interaction: } \mathbf{p C O}_{2} \text { \& total } \\
\text { VIGOR score }\end{array}$ & 0.00029 & 0.00013 & 0.00044 & 0.001 \\
\hline
\end{tabular}

Table 6: Multivariable linear regression model for the predictors of venous blood $\mathrm{pH}$ at $<2 \mathrm{~h}$ following birth in a sub-population of calves $(\mathrm{n}=34)$ 


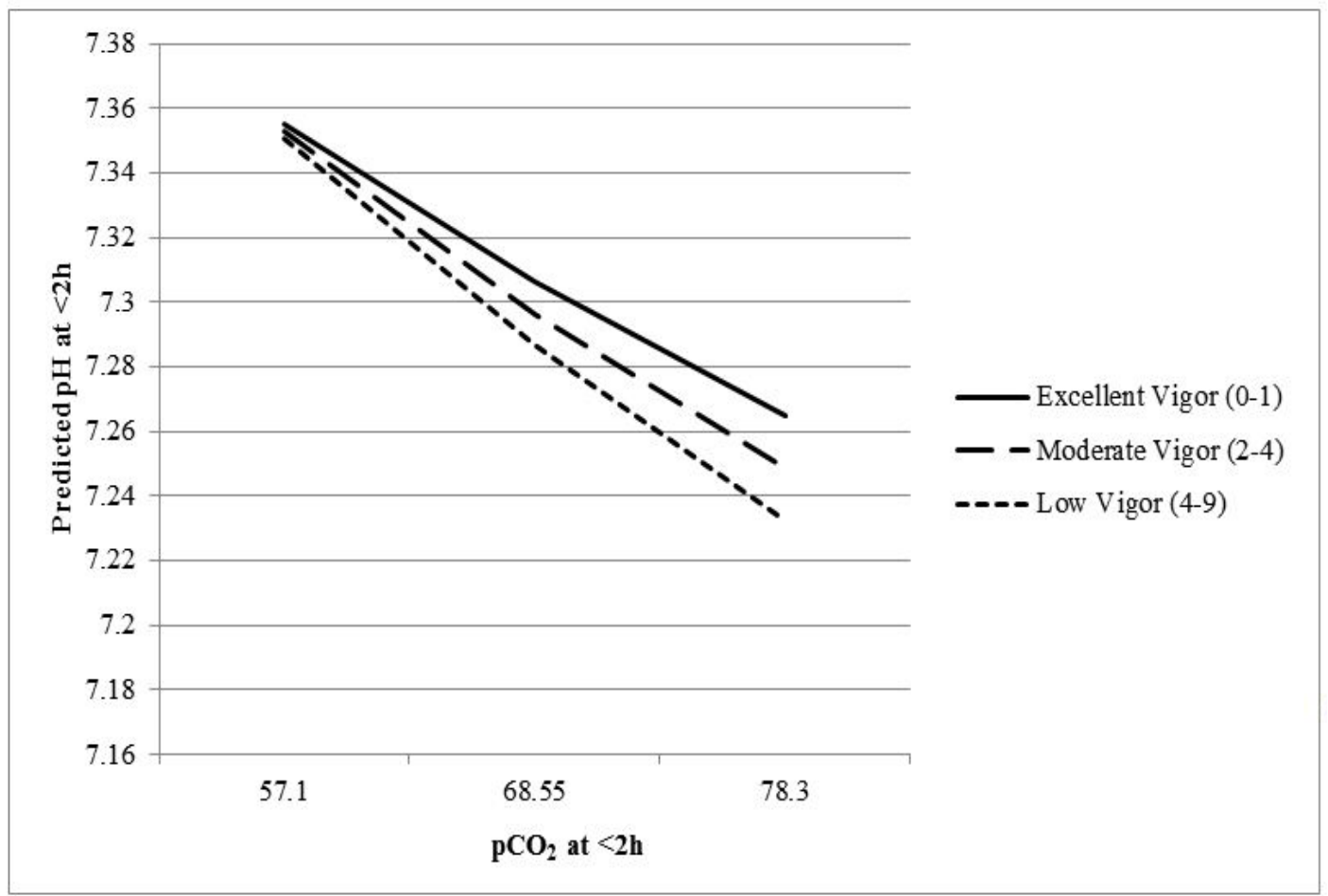

Figure 1: Predicted ${ }^{*}$ values for $\mathrm{pH}$ at $<2 \mathrm{~h}$ after birth while accounting for the interaction between VIGOR score at birth and the partial pressure of carbon dioxide $\left(\mathrm{pCO}_{2}\right)$ at $<2 \mathrm{~h}$.

${ }^{*}$ All other fixed effects in the multivariable model (see table 6) were set to their median values.

\section{Milk Intake}

Factors associated with higher milk intakes in a multivariable model included being on Farm 2, having $>2$ rewarded visits to the automated milk feeder, better health and treatment with meloxicam (Table 7).

\begin{tabular}{|c|c|c|c|c|}
\hline \multirow{2}{*}{$\begin{array}{c}\text { Square Root of Average } \\
\text { Milk Intake (L/d) }\end{array}$} & \multirow[t]{2}{*}{ Coefficient } & \multicolumn{2}{|c|}{ 95\% Confidence Interval } & \multirow[t]{2}{*}{$P$-value } \\
\hline & & lower limit & upper limit & \\
\hline \multicolumn{5}{|l|}{ Treatment } \\
\hline Meloxicam & 0.03 & 0.0016 & 0.057 & 0.039 \\
\hline Placebo & Ref & - & - & - \\
\hline Total 8 week health score & -0.0093 & -0.016 & -0.0034 & 0.002 \\
\hline \multicolumn{5}{|l|}{$\begin{array}{l}\text { Average \# of rewarded } \\
\text { visits to milk feeder/day }\end{array}$} \\
\hline 2 & Ref & - & - & - \\
\hline 4 & 0.080 & 0.050 & 0.11 & $<0.001$ \\
\hline 5 & 0.055 & 0.0093 & 0.10 & 0.019 \\
\hline \multicolumn{5}{|l|}{ Farm } \\
\hline 2 & 0.61 & 0.53 & 0.69 & $<0.001$ \\
\hline 1 & Ref & - & - & - \\
\hline
\end{tabular}

\section{Ref - Referent category}

Table 7: Multivariable linear regression model assessing the factors affecting the square root transformation of average milk intake per day for the first 30 days on the automated milk feeder $(n=222)$

\section{Calf Growth}

Weights from the $1^{\text {st }}$ and $8^{\text {th }}$ week were used to obtain average daily gain (ADG) over the follow-up period for each calf that remained in the herd for that duration. The mean $( \pm S D)$ ADG for calves from both farms over the 8 week period was $0.64 \pm 0.15 \mathrm{~kg} /$ day. The mean $( \pm \mathrm{SD})$ ADG by calving assistance can be seen in Table 3 . 
In a multivariable linear regression model, factors associated with reduced ADG included being a twin, having a greater heart rate at 1.5 to $4 \mathrm{~d}$ old, having a greater total health score (worse health) throughout the 8 week follow-up period, and fewer number of unrewarded visits to the automatic milk feeder. Calf presentation at calving confounded the effects of twin birth and heart rate and was included in the model. There was a significant difference in ADG by farm, with Farm 2 having significantly greater ADG. Treatment with meloxicam did not have a significant effect on ADG (Table 8).

\begin{tabular}{|c|c|c|c|c|}
\hline \multirow[t]{2}{*}{8 Week ADG (kg) } & \multirow[t]{2}{*}{ Coefficient } & \multicolumn{2}{|c|}{ 95\% Confidence Interval } & \multirow[t]{2}{*}{$P$-value } \\
\hline & & lower limit & upper limit & \\
\hline \multicolumn{5}{|l|}{ Twin birth } \\
\hline Yes & -0.15 & -0.23 & -0.073 & $<0.001$ \\
\hline No & Ref & - & - & - \\
\hline $\begin{array}{l}\text { Heart rate at } 1.5-4 \mathrm{~d} \text { old } \\
\text { (beats } / \mathrm{min})\end{array}$ & -0.00083 & -0.0015 & -0.00012 & 0.023 \\
\hline \multicolumn{5}{|l|}{${ }^{\star}$ Position at calving } \\
\hline Backward & -0.032 & -0.063 & 0.13 & 0.51 \\
\hline Forward & Ref & - & - & - \\
\hline Total 8 week health score & -0.016 & -0.024 & -0.0075 & $<0.001$ \\
\hline $\begin{array}{l}\text { Average \# of unrewarded } \\
\text { visits to milk feeder }\end{array}$ & 0.013 & 0.0076 & 0.019 & $<0.001$ \\
\hline \multicolumn{5}{|l|}{ Farm } \\
\hline 2 & 0.26 & 0.16 & 0.36 & $<0.001$ \\
\hline 1 & Ref & - & - & - \\
\hline \multicolumn{5}{|l|}{ Treatment } \\
\hline Meloxicam & 0.014 & -0.027 & 0.055 & 0.51 \\
\hline Placebo & Ref & - & - & - \\
\hline
\end{tabular}

\section{Ref - Referent category}

* Confounding variable

Table 8: Multivariable linear regression model of the predictor variables for ADG (kg) over the 8 week follow-up period $(\mathrm{n}=155)$

\section{Calf Health}

Fecal samples for the determination of shedding of fecal pathogens, Cryptosporidium parvum and rotavirus, were collected from 87 calves from Farm 1 at weeks 2 and 3 of age. In week 2, 47.1\% of the calves tested shed Cryptosporidium, whereas 1.2\% shed rotavirus. In week 3,51.7\% shed Cryptosporidium and 3.5\% shed rotavirus. There was no significant association between being treated with meloxicam and shedding Cryptosporidium in week 2 or rotavirus in week 2 or 3 . However, being treated with meloxicam was positively associated with shedding Cryptosporidium in week 3 ( $\beta=0.92 ; 95 \% \mathrm{CI}=0.046$ to $1.79 ; P=0.04$ ). Shedding Cryptosporidium in week 2 was significantly associated with having a higher total health score (worse health) at week 2 $(\beta=1.55 ; 95 \% \mathrm{CI}=0.85$ to $2.25 ; P<0.001)$.

Variables significantly associated with a higher total health score (worse health) up to 8 weeks of age included being born in the winter compared to the spring, being born a twin, having a higher rectal temperature at 3 weeks of age, being treated for diarrhea, and having a lower milk intake. Twin birth and milk intake were confounded by time of calving and drinking speed, respectively. Treatment with meloxicam was not significantly associated with an improvement in health over the 8 week study period (Table 9).

The percentage of calves having at least one course of antibiotic treatment for digestive and respiratory disease was $71.4 \%$ and $73.5 \%$, respectively. The number of courses of antibiotic treatments per calf was used to model factors influencing illness and treatment events (Table 10). Factors associated with the rate of antibiotic treatments included season of birth and milk intake. Calves born in the winter had a higher rate of treatment events compared to calves born in the spring. Also, calves having lower milk intakes had an increased rate of antibiotic treatment events over their duration on the study. Interestingly, days of age when milk intake data collection began (at movement to a group pen) did not confound milk intake. However, an older age at day 1 on the automatic feeder was significantly associated with increased treatment rates. 


\begin{tabular}{|c|c|c|c|c|}
\hline \multirow[t]{2}{*}{ Total 8 Week Health Score } & \multirow[t]{2}{*}{ Coefficient } & \multicolumn{2}{|c|}{ 95\% Confidence Interval } & \multirow[t]{2}{*}{$P$-value } \\
\hline & & lower limit & upper limit & \\
\hline \multicolumn{5}{|l|}{ Season of birth } \\
\hline Winter & 1.93 & 1.14 & 2.73 & $<0.001$ \\
\hline Spring & Ref & - & - & - \\
\hline \multicolumn{5}{|l|}{ Twin birth } \\
\hline Yes & 2.0 & 0.49 & 3.52 & 0.01 \\
\hline No & Ref & - & - & - \\
\hline \multicolumn{5}{|l|}{${ }^{\star}$ Time of calving } \\
\hline 4-10pm & -0.56 & -1.62 & 0.49 & 0.29 \\
\hline $10 \mathrm{pm}-4 \mathrm{am}$ & 0.38 & -0.70 & 1.46 & 0.49 \\
\hline 4-10am & -0.58 & -1.54 & 0.38 & 0.23 \\
\hline $10 \mathrm{am}-4 \mathrm{pm}$ & Ref & - & - & - \\
\hline $\begin{array}{l}\text { Week } 3 \text { rectal temperature } \\
\left({ }^{\circ} \mathrm{C}\right)\end{array}$ & 1.29 & 0.55 & 2.03 & $<0.001$ \\
\hline \multicolumn{5}{|l|}{ Treated for diarrhea } \\
\hline Yes & 1.0 & 0.042 & 1.96 & 0.041 \\
\hline No & Ref & - & - & - \\
\hline $\begin{array}{l}\text { Average milk intake for } \\
1^{\text {st }} 30 \mathrm{~d} \text { on the milk feeder } \\
\text { (L/d) }\end{array}$ & -1.0 & -1.76 & -0.24 & 0.01 \\
\hline $\begin{array}{l}{ }^{*} \text { Average drinking speed } \\
\text { from milk feeder }(\mathrm{L} / \mathrm{min})\end{array}$ & 0.21 & -1.61 & 2.03 & 0.82 \\
\hline \multicolumn{5}{|l|}{ Treatment } \\
\hline Meloxicam & -0.45 & -1.19 & 0.29 & 0.23 \\
\hline Placebo & Ref & - & - & - \\
\hline
\end{tabular}

\section{Ref - Referent category}

* Confounding variable

Table 9: Multivariable linear regression model of the predictor variables for total health score over the 8 week followup period $(\mathrm{n}=139)$

\begin{tabular}{|c|c|c|c|c|}
\hline Antibiotic Treatment & $\begin{array}{c}\text { Incidence Rate } \\
\text { Ratio }\end{array}$ & \multicolumn{2}{|c|}{ 95\% Confidence Interval } & P-value \\
\hline Season of birth & 1.33 & 1.09 & 1.62 & 0.004 \\
\hline Winter & Ref & - & - & - \\
\hline Spring & 0.70 & 0.61 & 0.81 & $<0.001$ \\
\hline $\begin{array}{c}\text { Average milk intake (L/d } \\
\text { for 1 } \mathbf{1}^{\text {st }} \mathbf{3 0} \text { d on feeder) }\end{array}$ & 1.02 & 0.61 & 0.81 & \\
\hline $\begin{array}{c}\text { Days of age on d 1 on the } \\
\text { milk feeder }\end{array}$ & & & & \\
\hline
\end{tabular}




\begin{tabular}{|c|c|c|c|c|}
\hline Antibiotic Treatment & $\begin{array}{c}\text { Incidence Rate } \\
\text { Ratio }\end{array}$ & \multicolumn{2}{|c|}{ 95\% Confidence Interval } & P-value \\
\hline Treatment & & lower limit & upper limit & \\
\hline Meloxicam & 1.03 & & & \\
\hline Placebo & Ref & - & 0.61 & - \\
\hline
\end{tabular}

\section{Ref - Referent category}

Table 10: Mulivariable Poisson regression model of the predictor variables for the number of antibiotic treatments over the 8 week follow-up period $(\mathrm{n}=242)$

\section{Discussion}

It has been suggested that calves born from a difficult birth may suffer from reduced vigor [10]. Reduced vigor may result in short and long-term consequences for the health and productivity of the calf, and economic losses for the producer. Thus, it is important to assess newborn calf vigor, as well as intervention strategies that can effectively reduce the negative implications of reduced vigor.

Methods to assess newborn calf vigor have focused on simple observations that can be assessed within minutes to provide surrogate measures of blood-gas status, and perhaps stress, pain, energy and motivation [15,17,22,23]. These types of observations have been included in the VIGOR score used in the current study. However, neither these specific observations, nor past assessment tools, have been validated as being accurate evaluations of newborn calf vigor. Many behaviors and physiological measurements included in the assessment tools, such as withdrawal reflex, movement after birth, body temperature, heart rate and respiration rate, have been shown to be indirect signs of pain and fatigue in farm animals [24].

It is expected that calves with reduced vigor, associated with the stress and trauma at calving, have some degree of pain and fatigue. Pain, inflammation and fatigue at calving can be the result of vertebral and rib fractures [9,25], hypoxia, acidosis [26-28] and a decrease in the newborn calf's ability to maintain thermoregulation [7,29]. In the current study, calves requiring assistance at birth, either an easy or hard pull, may have experienced these physiological repercussions, causing significantly reduced vigor, compared to calves unassisted at calving. In agreement with Murray et al. [16], calves born from a hard pull were at greater risk of reduced vigor compared to calves born from an easy pull or observed but unassisted at calving. Newborn calves experiencing reduced vigor due to trauma at birth may be at increased risk of stillbirth or have long-term consequences to health and productivity $[4,30,31]$. As such, it is important to minimize these consequences in the newborn calf with intervention strategies following calving.

The use of NSAIDs in calves following dystocia is a novel strategy to reduce the pain and inflammation associated with a difficult birth. Current research has been focused on the use of NSAIDs in the dam following calving $[18,32,33]$, whereas there has been little to no research to evaluate NSAID therapy in the newborn calf. Based on the current research, results suggest that NSAIDs may be beneficial to improve newborn calf vigor. In the sub-population of 61 calves in which a post-treatment VIGOR score was assessed, it was found that treatment with meloxicam resulted in greater improvements in vigor compared to placebo treated calves. This finding occurred when accounting for the time of the second VIGOR score assessment relative to birth, as the longer the recovery time, the more vigorous a calf is likely to become. However, the timing of treatment administration, VIGOR score assessment and the interval between all of these variables was inconsistent. This variability in time, along with the low sample size, indicates that there is a need for a more controlled study to confirm these results.

Decreased motivation to stand and suckle colostrum may be indicative of poor calf vigor. Barrier et al. [10] found that calves born with assistance took longer to attempt to stand for the first time, to achieve standing, to walk and to reach the udder. In addition, a study in puppies found that those with lower vitality scores were less likely to seek the mammary gland and had weaker suckling/swallowing reflexes [14]. Low motivation to reach the udder and consume colostrum may have long-term implications on performance in calves with failure of passive transfer (FPT) [31]. As such, it has been recommended that suckling behavior be used to assess calf vigor, either as a stand-alone parameter, or as a part of a modified Apgar score [34]. Since that time, suckling reflex has been incorporated into an assessment of newborn calf vitality [17]. In the current study, suckling reflex was not included in the VIGOR score, nor was it associated with the VIGOR score. However, it was found that calves treated with meloxicam had significantly improved suckling reflexes based on the finger test. Although not significant, a similar direction of this effect was noted with the manometer measurements. This finding is in accordance with the improved vigor seen in meloxicam treated calves. It was hypothesized that pain and inflammation following a difficult birth may be relieved in calves treated with meloxicam. Thus, these calves would have improved vigor and motivation to consume colostrum.

It has been suggested that vigor is decreased in newborns experiencing acidosis [12,22,26]. In calves that do not have sufficient blood oxygenation, fetal tissues will derive energy from anaerobic glycolysis, which results in the production of lactic acid and leads to metabolic acidosis $[27,28]$. In the current study, an interaction was found between calf VIGOR score following birth and $\mathrm{pCO}_{2}$ with blood $\mathrm{pH}<2 \mathrm{~h}$ following birth. This finding suggests that as $\mathrm{pCO}_{2}$ increases, calves with reduced vigor have a steeper drop in blood $\mathrm{pH}$ compared to calves with better vigor. However, no calves in the study were severely acidotic $(\mathrm{pH}<7.0)$, and very few ( 6 calves) were moderately acidotic ( $\mathrm{pH}$ between 7.0 and 7.2$)<2 \mathrm{~h}$ following birth. If blood-gas samples were collected immediately after birth, it is likely that more calves would fit into the moderately and severely acidotic categories. In agreement with this concept, Schuijt and Taverne [22] took blood-gas samples at $10 \mathrm{~min}$ after birth and found that both mean $\mathrm{pH}$ and baseexcess values of non-vital calves differed significantly from those of vital calves. Although not significant, the $\mathrm{pCO}_{2}$ values were al- 
so consistently higher in non-vital calves [22]. A similar relationship was seen in newborn piglets, as those with increased acidosis and hypercapnia had reduced viability following birth [12]. Other studies, not investigating newborn vigor specifically, remain in agreement that $\mathrm{pCO}_{2}$ immediately after birth is significantly associated with the degree of acidosis $[28,35]$.

Hypoxia and acidosis have been associated with decreasing the available energy that is needed for the metabolic activity of brown adipose tissue required to maintain thermoregulation in the newborn calf [7]. Stott and Reinhard [29] found that severe hypoxia can reduce muscle tonicity and prevent shivering following birth. Other studies have suggested that the degree of stress at calving, calving environment and season of birth can impair a calf's ability to mobilize energy reserves to achieve homeostasis [36]. Diesch et al. [37] found that the calving environmental conditions affected calf vigor. Calves born in temperatures below $10^{\circ} \mathrm{C}$, or in windy/wet conditions, were slower to stand after birth than calves born in temperatures greater than $10^{\circ} \mathrm{C}$, or in still/dry or windy/ dry conditions [37]. Although the current study did not find an association between being born in the winter and calf VIGOR score, calves born in the winter had reduced health and required a greater number of antibiotic treatments compared to calves born in the spring. This is in agreement with Lombard et al. [5], who found that heifer calves born in the winter were more likely to experience either respiratory or digestive disease, and/or die before $120 \mathrm{~d}$ of age, compared to calves born in the fall. Temperature fluctuations, temperature extremes and an increased susceptibility to cold stress from a failure to thermoregulate, may compromise a calf's ability to defend against pathogens that cause disease.

Measuring heart rate in calves can be used as a quick and easy determinant of health and vigor. Studies investigating heart rate in calves have primarily been focused on heart rate during calving or at birth. Mee and Smith [17] suggested that a regular heart rate of 100-150 bpm indicates good newborn calf vitality, whereas a rate of $>150 \mathrm{bpm}$ followed by an irregular decreasing rate $(<80$ bpm) indicates poor vitality. This is based from findings by Szenci [38], that at risk calves had peripartum tachycardia (>150 bpm) followed by a declining bradycardia. However, it is interesting that Mohr et al. [39] analyzed the heart rate of calves 5 to 10 days of age and found that heart rate increased significantly in calves under temperature and insect stress, and even more so in calves with diarrhea. In the current study, it is possible that calves with a high heart rate at 3 weeks of age were experiencing environmental and/or health stress and those high heart rates had an indirect effect on decreasing ADG through stress.

Long term consequences of stress at calving and reduced newborn vigor may decrease ADG. Reduced vigor in the newborn calf has been shown to decrease a calf's motivation to consume colostrum at birth or impair Ig absorption leading to FPT and a weakened immune system $[7,8,40]$. A weakened immune system can increase the calf's susceptibility to disease, increasing energy requirements for maintenance that could have otherwise gone towards growth [31,41]. In the current study, reduced vigor, weak suckling reflex and STP were not significantly associated with reduced ADG. It is possible that the VIGOR score was not suitable for making long-term predictions of ADG.

Calves treated with meloxicam in the current study had significantly greater milk intake. Todd et al. [42] found that calves treated with meloxicam at the onset of diarrhea had improved starter and milk intakes. During disease, pro-inflammatory cytokines causing a loss of appetite are blocked by meloxicam, causing increased motivation to exhibit feeding behavior [42]. However, in the current study, meloxicam was administered at birth. Since meloxicam has a half-life of $26 \mathrm{~h}$ in young cattle, it is unlikely that the anti-inflammatory effects would have a direct effect on feeding behavior 2 to 6 weeks later. However, it may be possible that calves treated with meloxicam at birth, that had an improved suckling reflex, carried this motivation to drink throughout the preweaning period.

\section{Conclusion}

The calf VIGOR scoring system shows promise for the successful identification of calves with reduced newborn vigor resulting from an assisted calving. Calves with reduced vigor were more acidotic at high $\mathrm{pCO}_{2}$ levels than calves with better vigor. Calves treated with meloxicam following birth had greater improvements in vigor and suckling reflex than placebo treated calves. Lower ADG was associated with reduced health, which may be because calves with high health scores (worse health) and increased antibiotic treatment events for diarrhea and/or respiratory disease, had lower average milk intakes per day. Calves treated with meloxicam had greater milk intakes, and calves with greater milk intakes had greater ADG. Thus, meloxicam therapy shows considerable promise for improving short-term challenges with newborn vigor, as well as improving milk intake which may lead to greater weight gains and improved long-term productivity.

\section{Acknowledgement}

This study was funded by Boehringer Ingelheim (Canada) Ltd., along with the Agriculture Adaptation Council through the Ontario Veal Association. The authors declare no conflict of interest.

\section{References}

1. Breazile J, Vollmer LA, Rice LE (1988) Neonatal adaptation to stress of parturition and dystocia. Vet Clin North Am Food Anim Pract 4: 481-99.

2. Mee JF (2008) Prevalence and risk factors for dystocia in dairy cattle: a review. Vet J 176: 93-101.

3. Mee JF (2004) Managing the dairy cow at calving time. Vet Clin North Am Food Anim Pract 20: 521-46.

4. Meyer CL, Berger PJ, Koehler KJ, Thompson JR, Sattler CG (2001) Phenotypic trends in incidence of stillbirth for Holsteins in the United States. J Dairy Sci 84: 515-23.

5. Lombard JE, Garry FB, Tomlinson SM, Garber LP (2007) Impacts of dystocia on health and survival of dairy calves. J Dairy Sci 90: $1751-60$.

6. Murray CF, Leslie KE (2013) Newborn calf vitality: Risk factors, characteristics, assessment, resulting outcomes and strategies for improvement. Vet J 198 : 322-8. 
7. Vermorel M, Vernet J, Saido, Dardillat C, Demigné C, et al. (1989) Energy metabolism and thermoregulation in the newborn calf; effect of calving conditions. Can J Anim Sci 69: 113-22.

8. Besser TE, Szenci O, Gay CC (1990) Decreased colostral immunoglobulin absorption in calves with postnatal respiratory acidosis. J Am Vet Med Assoc 196: 1239-43.

9. Schuijt G (1990) Iatrogenic fractures of ribs and vertebrae during delivery in perinatally dying calves: 235 cases (1978-1988). J Am Vet Med Assoc 197: 1196-202. 10. Barrier AC, Ruelle E, Haskell MJ, Dwyer CM (2012) Effect of a difficult calving on the vigour of the calf, the onset of maternal behaviour, and some behavioural indicators of pain in the dam. Prev Vet Med 103: 248-56.

11. Apgar V, Holaday DA, James LS, Weisbrot IM, Berrien C (1958) Evaluation of the newborn infant-second report. J Am Med Assoc 168: 1985-8.

12. Randall GC (1971) The relationship of arterial blood $\mathrm{pH}$ and $\mathrm{pCO}_{2}$ to the viability of the newborn piglet. Can J Comp Med 35: 141-6.

13. Veronesi MC, Riccaboni P, Faustini M, Battocchio M, Cairoli F, et al. (2005) Potential association between placental features and apgar scores after normal parturition in the thoroughbred horse. J Anim Vet Adv 4: 965-70.

14. Veronesi MC, Panzani S, Faustini M, Rota A (2009) An Apgar scoring system for routine assessment of newborn puppy viability and short-term survival prognosis. Theriogenology 72: 401-7.

15. Mulling VM (1977) Asphyxia of newborn calves. Der Praktische Tierarzt 58: 78-80.

16. Murray CF, Haley DB, Duffield TF, Pearl DL, Deelen SM, et al. (2015) A field study to evaluate the effects of meloxicam NSAID therapy and calving assistance on newborn calf vigor, improvement of health and growth in pre-weaned Holstein calves. The Bovine Practitioner 49: 1-12.

17. Mee JF, Smith RA (2008) Managing the calf at calving time Proceedings of the 41st Annual Conference of the American Association of Bovine Practitioners, Charlotte, North Carolina, USA, 46-53.

18. Laven R, Chambers P, Stafford K (2012) Using non-steroidal anti-inflammatory drugs around calving: Maximizing comfort, productivity and fertility. Vet J 192: 8-12.

19. Hudson C, Whay H, Huxley J (2008) Recognition and management of pain in cattle. In Pract 30: 126-34.

20. CCAC (Canadian Council on Animal Care) (2009) CCAC Guidelines On: The Care and Use of Farm Animals in Research, Teaching and Testing. Ottawa, Canada.

21. McGuirk SM (2008) Disease management of dairy calves and heifers. Vet Clin North Am Food Anim Pract 24: 139-53.

22. Schuijt G, Taverne MA (1994) The interval between birth and sternal recumbency as an objective measure of the vitality of newborn calves. Vet Rec 135: 111-5.

23. Herfen K, Bostedt H (1999) Correlation between clinical and laboratory diagnostic evaluation of the vitality of newborn calves under particular consideration of length and type of parturition. Wien Tierarztl Monatsschr 86: 255-61.

24. Molony V, Kent JE (1997) Assessment of acute pain in farm animals using behavioral and physiological measurements. J Anim Sci 75: 266-72.

25. Schuh JC, Killeen JR (1988) A retrospective study of dystocia-related vertebral fractures in neonatal calves. Can Vet J 29: 830-3.

26. Szenci O (1982) Correlations between muscle tone and acid-base balance in newborn calves: Experimental substantiation of a simple new score system proposed for neonatal status diagnosis. Acta Vet Acad Sci Hung 30: 79-84.

27. Grove-White D (2000) Resuscitation of the newborn calf. In Pract 22: 17-23.

28. Bleul U, Lejeune B, Schwantag S, Kähn W (2007) Blood gas and acid-base analysis of arterial blood in 57 newborn calves. Vet Rec 161: 688-91.

29. Stott GH, Reinhard EJ (1978) Adrenal function and passive immunity in the dystocial calf. J Dairy Sci 61: 1457-61.

30. Tenhagen BA, Helmbold A, Heuwieser W (2007) Effect of various degrees of dystocia in dairy cattle on calf viability, milk production, fertility and culling. J Vet Med A Physiol Pathol Clin Med 54: 98-102.

31. Furman-Fratczak K, Rzasa A, Stefaniak T (2011) The influence of colostral immunoglobulin concentration in heifer calves' serum on their health and growth. J Dairy Sci 94: 5536-43.

32. Shwartz G, Hill KL, VanBaale MJ, Baumgard LH (2009) Effects of flunixin meglumine on pyrexia and bioenergetic variables in postparturient dairy cows. J Dairy Sci 92: 1963-70.

33. Newby NC, Pearl DL, Leblanc SJ, Leslie KE, von Keyserlingk MA, et al. (2013) Effects of meloxicam on milk production, behavior, and feed intake in dairy cows following assisted calving. J Dairy Sci 96: 3682-8.

34. Schulz J, Plischke B, Braun H (1997) Sucking and drinking behavior as criteria of vitality in newborn calves. Tierärztliche Prax 25: 116-22.

35. Szenci O, Taverne MA, Bakonyi S, Erdodi A (1988) Comparison between pre- and postnatal acid-base status of calves and their perinatal mortality. Vet Q 10: $140-4$.

36. Okamoto M, Robinson JB, Christopherson RJ, Young BA (1986) Summit metabolism of newborn calves with and without colostrum feeding. Can J Anim Sci 66: 937-44.

37. Diesch TJ, Mellor DJ, Stafford KJ, Ward RN (2004) The physiological and physical status of single calves at birth in a dairy herd in New Zealand. NZ Vet J 52: 250-5.

38. Szenci O (2003) Role of acid-base disturbances in perinatal mortality of calves: a review. Vet Bullet 73: 7R-14R.

39. Mohr E, Langbein J, Nürnberg G (2002) Heart rate variability: a noninvasive approach to measure stress in calves and cows. Physiol Behav 75: 251-9.

40. Beam AL, Lombard JE, Kopral CA, Garber LP, Winter AL, et al. (2009) Prevalence of failure of passive transfer of immunity in newborn heifer calves and associated management practices on US dairy operations. J Dairy Sci 92: 3973-80.

41. Wittum TE, Perino LJ (1995) Passive immune status at postpartum hour 24 and long-term health and performance of calves. Am J Vet Res 56: 1149-54.

42. Todd CG, Millman ST, McKnight DR, Duffield TF, Leslie KE (2010) Nonsteroidal anti-inflammatory drug therapy for neonatal calf diarrhea complex: Effects on calf performance. J Anim Sci 88: 2019-28. 


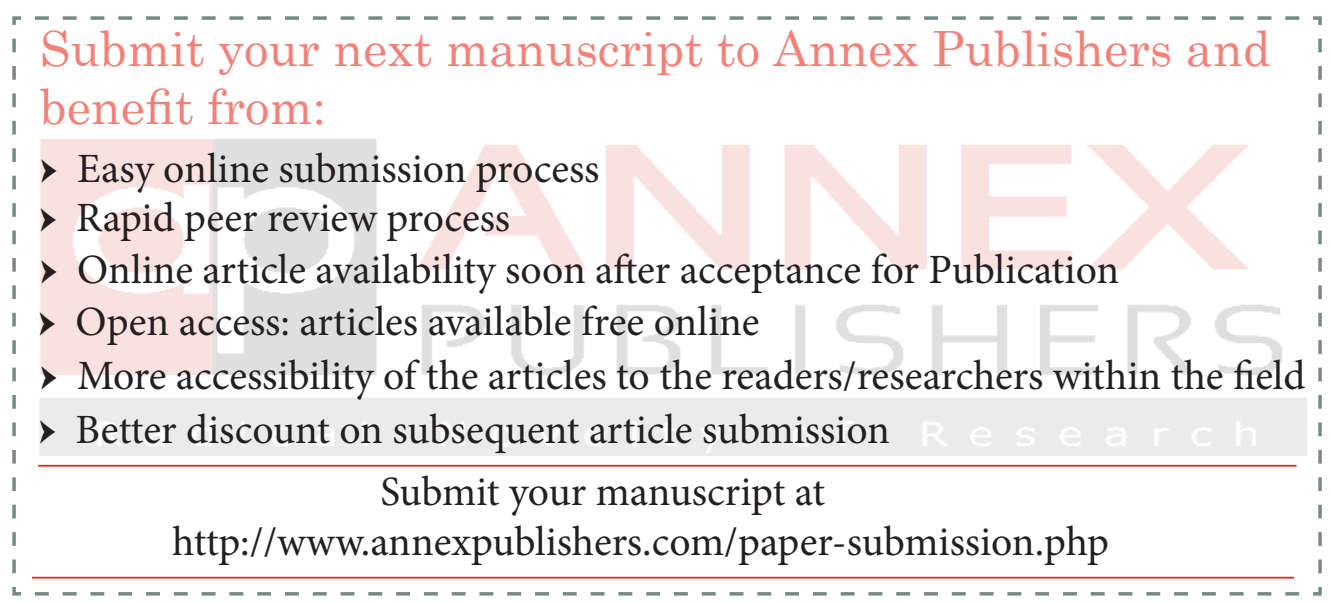

